\title{
The cognitive loci of the display and task-relevant set size effects on distractor interference: Evidence from a dual-task paradigm
}

\author{
Bo Youn Park ${ }^{1} \cdot$ Sujin Kim $^{1}$ - Yang Seok Cho ${ }^{1}$
}

Published online: 9 November 2017

(C) The Psychonomic Society, Inc. 2017

\begin{abstract}
The congruency effect of a task-irrelevant distractor has been found to be modulated by task-relevant set size and display set size. The present study used a psychological refractory period (PRP) paradigm to examine the cognitive loci of the display set size effect (dilution effect) and the taskrelevant set size effect (perceptual load effect) on distractor interference. A tone discrimination task (Task 1), in which a response was made to the pitch of the target tone, was followed by a letter discrimination task (Task 2) in which different types of visual target display were used. In Experiment 1, in which display set size was manipulated to examine the nature of the display set size effect on distractor interference in Task 2 , the modulation of the congruency effect by display set size was observed at both short and long stimulus-onset asynchronies (SOAs), indicating that the display set size effect occurred after the target was selected for processing in the focused attention stage. In Experiment 2, in which taskrelevant set size was manipulated to examine the nature of the task-relevant set size effect on distractor interference in Task 2, the effects of task-relevant set size increased with SOA, suggesting that the target selection efficiency in the preattentive stage was impaired with increasing task-relevant set size. These results suggest that display set size and taskrelevant set size modulate distractor processing in different ways.
\end{abstract}

Keywords Attention: Selective $\cdot$ Dual task procedures(PRP) · Dual-task performance

Yang Seok Cho

yscho_psych@korea.ac.kr

1 Department of Psychology, Korea University, 145 Anam-ro, Seongbuk-Gu, Seoul 02841, Korea
Attentional selection has been a fundamental issue in the study of attention and information processing, which has been regarded as having limited capacity. A great deal of scholarly concern has focused on when and how task-relevant information is selected. Various theories, such as early and late selection theories, have provided different views regarding the degree to which unselected items are processed. According to the early selection theory, physical characteristics of all incoming stimuli are processed in a preattentive stage in a parallel way, and only the selected item is identified one at a time at a focused attention stage and unselected items are filtered out before identification (Broadbent, 1958). However, the late selection theory claims that task-irrelevant stimuli are not excluded at the identification stage, and that attention is required to select a response after all incoming stimuli are identified in parallel (Deutsch \& Deutsch, 1963; Norman, 1968). Many lines of evidence have been provided for and against both views, with the locus of selection the subject of much debate.

Lavie and Tsal (1994) proposed the perceptual load theory to explain the discrepancies in the evidence for the two different views to the question of selective attention. The perceptual load theory assumes that perceptual information is automatically processed until a limited amount of attentional resources is exhausted because the perceptual process is subject to attentional limited capacity but is not controlled voluntarily. Thus, when perceptual load is low, the processing of taskrelevant stimuli leaves spare capacity, and leftover attentional resource is automatically allocated to task-irrelevant stimuli. However, when perceptual load is high, attentional resource is unavailable for task-irrelevant stimuli after this resource has been allocated to the task-relevant stimuli (Lavie, 1995). In her Experiment 1, in which perceptual load was manipulated by changing task-relevant set sizes in the search display, Lavie examined the amounts of distractor interference with high and low task-relevant set sizes. When task-relevant set size was 
low, the target was presented in one of six possible positions with a distractor that either matched or did not match the target, appearing at a task-irrelevant peripheral position. When it was high, the target was presented in one of six possible positions with five neutral stimuli presented in the other five possible positions and a distractor appearing in a peripheral position. Lavie found that distractor interference was obtained when task-relevant set size was low but not when it was high - the so-called the perceptual load effect. According to the perceptual load theory, the processing of a task-irrelevant distractor is modulated by the amount of the perceptual load for task-relevant stimuli, such as task-relevant set size. Since the perceptual load theory was first introduced, many subsequent studies have provided evidence for the role of perceptual load in attentional selection (e.g., Beck \& Lavie, 2005; Forster \& Lavie, 2008a, b, 2009; Lavie, 1995; Lavie \& Cox, 1997; Wei, Kang, \& Zhou, 2013; for review, see Murphy, Groeger, \& Greene, 2016).

However, numerous other studies have also reported evidence against the perceptual load theory. For example, Johnson, McGrath, and McNeil (2002) found that early selection occurred in a low perceptual load context when participants knew the target location in advance. Eltiti, Wallace, and Fox (2005) also demonstrated that distractor interference disappeared even in a low task-relevant set size display when the properties of the distractor were in discord with attentional control settings for the target. Importantly, Tsal and Benoni (2010a) argued that the modulation of the distractor interference effect by task-relevant set size was actually due to dilution, which is a reduced distractor interference effect with increased display set size (Brown, Roos-Gilbert, \& Carr, 1995; Cho, Lien, \& Proctor, 2006; Kahneman \& Chajczyk, 1983), rather than being a result of the perceptual load of the task-relevant stimuli. That is, according to the latter authors, the perceptual load effect obtained in experiments manipulating task-relevant set size was confounded with the effect of display set size. To dissociate the effect of display set size from the effect of task-relevant set size on distractor interference, Tsal and Benoni added another display called as the dilution display, in which a target and several neutral stimuli were presented in task-relevant positions with a distractor presented in a task-irrelevant peripheral position, as in the high task-relevant set size display. However, as the color of the target was different from all other stimuli, the task-relevant set size was low but the display set size was high.

Tsal and Benoni (2010a) found that the magnitude of the congruency effect was significantly greater when the display set size was low than when it was high, but its magnitude was significantly greater when the task-relevant set size was high than when it was low. In other words, the processing of the task-irrelevant distractor was modulated by display set size when task-relevant set size was controlled - the so-called the dilution effect. Moreover, when display set size was controlled, the amount of the congruency effect increased as a function of task-relevant set size, a finding that is inconsistent with Lavie's (1995) original perceptual load theory. They suggested that as display set size increases the amount of dilution increases, resulting in decreased distractor interference. These display set size effect (e.g., Benoni \& Tsal, 2010; Benoni, Zivony, \& Tsal, 2014; Biggs \& Gibson, 2014; Wilson, Muroi, \& MacLeod, 2011) and reversed task-relevant set size effect on distractor interference (Benoni \& Tsal, 2012; Wilson et al., 2011) were replicated in numerous other studies. Although Lavie and Torralbo (2010) proposed a spillover hypothesis to explain the results obtained by Tsal and Benoni (2010a), according to which spare capacity was allocated to neutral stimuli instead of the distractor when the display set size was high due to salience or proximity, Tsal and Benoni (2010b) criticized the spillover hypothesis with evidence that those factors did not impact on the processing of the distractor-an outcome that was inconsistent with the hypothesis.

To explain the display set-size effect on distractor processing, Tsal and Benoni (2010a) used Brown et al.'s (1995) early visual interference account, which was proposed to explain the Stroop dilution effect. The Stroop dilution effect is a reduced Stroop effect that occurs when a neutral word is presented with a target color carrier and a color word compared to the effect when no neutral word is presented. According to the visual interference account, even though letter (word) recognition occurs automatically, feature representations of stimuli other than the target interfere with each other at an early visual processing stage when multiple stimuli are presented simultaneously in a display. Thus, because of these degraded feature representations, the identification processing of the distractor is degraded, resulting in a reduced Stroop effect when a neutral word is presented with a color carrier and a color word. Wilson et al. (2011) also suggested that the modulation of distractor interference was due to dilution. However, they proposed a two-stage dilution hypothesis, suggesting that dilution operates not only in an early visual processing stage but also in the focused attention stage. According to Wilson et al., because the target is selected in the focused attention stage, all other items in the display are subject to dilution, so that dilution at this stage also increases with display set size. Similarly, Cho et al. (2006) suggested that the Stroop dilution occurs because of the attentional competition between the distractor and neutral stimuli at the focused attention stage. However, because Tsal and Benoni (2010a, b), and Wilson et al. (2011) did not directly examine the nature of dilution, it is unclear whether dilution was due to perceptual crosstalk in the preattentive stage or limited attentional capacity in the focused attention stage.

Meanwhile, Tsal and Benoni (2010a) assumed that the reversed task-relevant set-size effect on distractor interference was a result of task difficulty. They proposed that, because the 
uncertainty of the target location increases with the number of task-relevant stimuli during information processing in the preattentive stage (Wilson et al., 2011), the time window for distractor intrusions also increases, resulting in an increase in the amount of distractor interference. Unlike the prediction based on the perceptual load theory, Tsal and Benoni (2010a) and Wilson et al. (2011) suggested that task-relevant set-size increases the probability of the misallocation of attention to the distractor location before the target is selected.

In the present study, the nature of the display set-size effect on distractor interference was examined while controlling the effect of task-relevant set-size and the nature of the taskrelevant set-size effect on distractor interference while controlling the effect of display set-size. Specifically, to see whether the display set-size and the task-relevant set-size effects on distractor interference were due to factors affecting information processing at the preattentive stage or other factors affecting information processing at the focused attention stage, the dual-task paradigm was used. The dual-task paradigm has been used widely to examine the capacity-free automaticity or whether a factor affects information processing in the preattentive stage or the focused attention stage (Davis, 1957; Welford, 1952; for review, see Lien \& Proctor, 2002). In this paradigm, in which participants are instructed to make responses rapidly for two different simple tasks, Task 1 (T1) and Task 2 (T2), the stimulus-onset asynchrony (SOA) between the onset of the target stimulus (S1) for T1 and the onset of the target stimulus (S2) for T2 is manipulated. The typical finding in the dual-task paradigm is that the response (R2) for $\mathrm{T} 2$ is substantially slowed at short SOAs compared to R2 at long SOAs. This phenomenon is called the psychological refractory period (PRP) effect.

It has been suggested that this PRP effect is due to a central bottleneck in human information processing systems. In the processing stages before the bottleneck, information processing occurs for T1 and T2 simultaneously. However, in the processing stage, at which the bottleneck is located, information processing occurs for only one task at a time. Thus, at short SOAs, information processing for T2 at this stage must wait until processing for T1 is completed, resulting in delayed R2. The amount of time during which no information processing occurs is called "slack" (Schweickert, 1983; see Fig. 1a). Because the amount of slack decreases as SOA increases, R2 becomes faster as SOA increases. Using this logic of the central bottleneck, it has been investigated whether information processing of $\mathrm{T} 2$ at a specific stage occurs before or after the bottleneck (e.g., Lien, Ruthruff, \& Johnston, 2006; McCann, Remington, \& Van Selst, 2000). Specifically, when manipulating a variable that is supposed to affect information processing at a processing stage before the bottleneck, the effect of this variable on R2 decreases at short SOAs (underadditive effect) because the effect is absorbed into the slack (Pashler, 1994; Schweickert, 1978). However, if the variable affects information processing at a post-bottleneck processing stage, the effect of this variable on $\mathrm{R} 2$ should be additive with SOA (see Fig. 1b).

In the present study, participants were asked to perform a tone discrimination task as $\mathrm{T} 1$ and a letter discrimination task as T2. The critical manipulation was the display type of T2. In Experiment 1, as in Tsal and Benoni's (2010a) Experiment 1b, display set-size was manipulated to ascertain whether the effect of display set size on distractor interference is attributable to perceptual crosstalk at the preattentive stage or to limited attentional capacity at the focused attention stage. If the display set-size effect on distractor interference is a result of degraded feature representations, the display set size of T2 would affect distractor interference underadditively with SOA. However, if the display set size effect is a result of limited attentional capacity, it would affect distractor interference additively with SOA. In Experiment 2, as in the high load and dilution displays used in Tsal and Benoni's Experiment $1 \mathrm{~b}$, task-relevant set size was manipulated to examine the nature of the task-relevant set size effect on distractor interference. If task-relevant set size increases the probability of distractor intrusions at the preattentive stage because of an impaired target selection efficiency, task-relevant set size would affect distractor interference underadditively with SOA.

\section{Experiment 1: the effect of display set size}

To examine whether the display set size effect on distractor interference occurs at an early visual processing stage before the central bottleneck stage, as Tsal and Benoni (2010a) claimed, or whether it occurs at a post-bottleneck stage, as Wilson et al. (2011) suggested, the present experiment adopted the dual-task paradigm with a manipulation of display set size, as in the low load and dilution displays used in Tsal and Benoni's Experiment 1b. In the present experiment, participants were asked to perform a tone-discrimination task as $\mathrm{T} 1$ and a letter discrimination task as T2 serially. SOA between the onsets of S1 and S2 was manipulated. The participants were instructed to make a response (R1) to the pitch of S1 first with one hand, and a response (R2) to the identity of the target letter with the other hand. In the letter discrimination task, there were two levels of display set size: low and high. When the display set size was low, the target display contained a target letter, which was positioned at one of four possible central locations, and a distractor, which was positioned at a left or right peripheral location. When the display set size was high, a colored target letter and three white neutral letters were presented at central positions and a distractor was presented at a peripheral location. Because the target was distinguished from the neutral letters by color in the high set size display, the task-relevant set size was same as the low display set size 


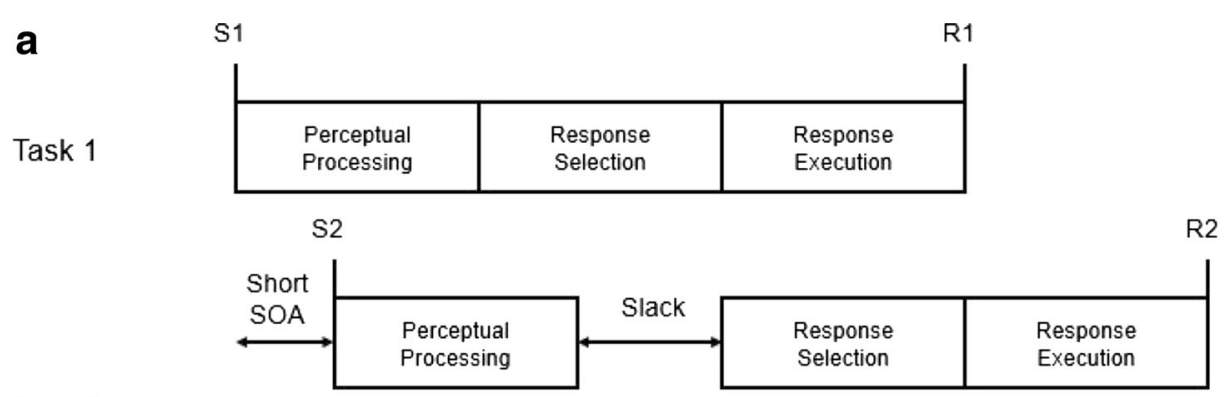

Task 2

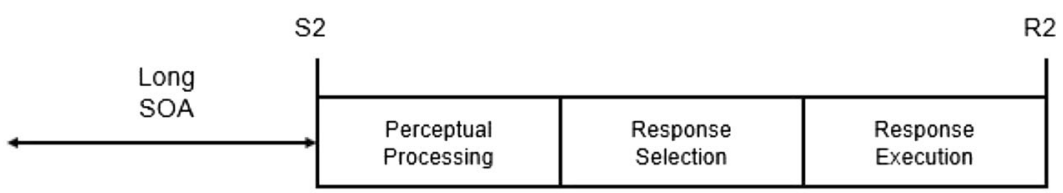

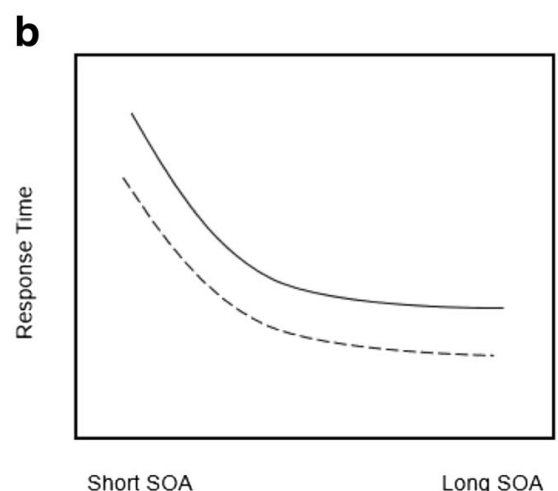

Fig. 1 a The central bottleneck model in the psychological refractory period (PRP) paradigm. The central bottleneck stage of Task 2 cannot begin until the central processing of Task 1 is completed, resulting in cognitive slack at short SOA. S1 Stimulus for Task 1, S2 stimulus for Task 2, $R 1$ response for Task $1, R 2$ response for Task 2, SOA stimulus

display. The display set size effect on distractor interference could therefore be examined through a comparison between the congruency effects with the low and high display set sizes.

If display set size affects the degree to which the distractor is processed before the target letter is selected for processing at the focused attention stage, as Tsal and Benoni (2010a) claimed, the display set size effect on distractor interference would increase with SOA because longer perceptual and letter recognition processes for the distractor are possible at short SOAs than at long SOAs (e.g., Levy \& Pashler, 1995), resulting in slack absorbing the effect of perceptual crosstalk. However, if the display set size effect on distractor interference is due to limited central attentional capacity as Wilson et al. (2011) claimed, the amounts of the modulation of distractor interference by display set size would be constant across SOAs because the display set size effect on distractor interference is due to attentional competition among all visual items for central attentional resources except the target letter after the target is selected for further processing at the focused attention stage.

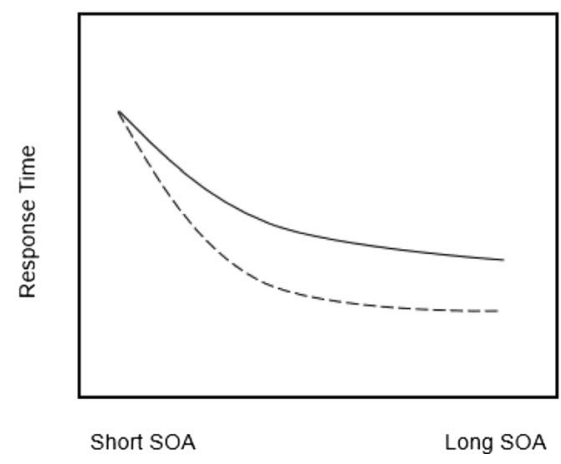

onset asynchrony. b The expected results from the central bottleneck model. Left panel Additive effect with SOA when any factors affecting the stage after the bottleneck stage. Right panel Underadditive effect with SOA when any factors affecting the stage before the bottleneck stage

\section{Method}

\section{Participants}

Forty students (21 females) from Korea University with an age range between 18 and 29 years old participated and provided informed consent, as approved by the Institutional Review Board of Korea University (IRB Number: KU-IRB15-47-A-1). All had normal or corrected-to-normal visual acuity and color vision by self-report.

\section{Apparatus}

The experiment was conducted in a dimly lit room. Visual stimuli were presented on a 15.9-in. CRT monitor (LG IBM FLATRON 1771FT) with a refresh rate of $60 \mathrm{~Hz}$, and auditory stimuli were presented on speakers (PILLAR CS-3000 PLUS). Responses were collected via a standard computer keyboard. Stimuli presentation, timing, and data collection were controlled by E-Prime software (E-Prime 2.0, 
Psychology Software Tools, Inc., Pittsburgh, PA). The viewing distance was approximately $60 \mathrm{~cm}$.

\section{Stimuli}

All stimuli were presented on a black background. The fixation mark was a white cross $\left(0.46^{\circ} \times 0.46^{\circ}\right)$. The interval between the onset of the target stimuli for T1 and T2 (stimulus onset asynchrony, SOA) was manipulated as $50 \mathrm{~ms}, 100 \mathrm{~ms}$, $300 \mathrm{~ms}, 700 \mathrm{~ms}$, and $1100 \mathrm{~ms}$. T1 was a tone discrimination task. When a tone was presented through speakers, participants were to respond to the pitch of the tone by pressing a left or right key. There was no reference tone, and only one low tone $(498 \mathrm{~Hz})$ and one high tone $(661 \mathrm{~Hz})$ were presented for $50 \mathrm{~ms}$ in $\mathrm{T} 1$. T2 was a visual letter discrimination task, similar to Tsal and Benoni's (2010a) Experiment 1b. In T2, participants were to respond to the identity of the target letter in the square array. $\mathrm{C}, \mathrm{S}, \mathrm{H}$, or $\mathrm{K}$ was presented as a target letter $\left(0.58^{\circ} \times 0.7^{\circ}\right)$. Two letters $(\mathrm{C}$ and $\mathrm{S})$ were assigned to one response and the other two letters $(\mathrm{H}$ and $\mathrm{K})$ to the other response. Two types of display were distinguished based on the number of letters in the array. The first display type was a low set size display with a target letter $(\mathrm{C}, \mathrm{S}, \mathrm{H}$, or $\mathrm{K})$ in the central square array $\left(0.58^{\circ} \times 0.7^{\circ}\right)$ and a distractor letter $(\mathrm{C}, \mathrm{S}$, $\mathrm{H}$, or $\mathrm{K})$ to the left or right of the central array $\left(0.8^{\circ} \times 1^{\circ}\right)$. The target and distractor letters differed from one another in every case. A distractor was located at $3.08^{\circ}$ from fixation. The target and distractor were presented in white. The second display type was a high set size display, which had a target letter $\left(0.58^{\circ} \times .7^{\circ}\right)$ and three neutral letters $\left(0.58^{\circ} \times 0.7^{\circ}\right)$ from a set of $\mathrm{D}, \mathrm{N}, \mathrm{U}$, and $\mathrm{Z}$ in the central array and a distractor letter $\left(0.8^{\circ} \times 1^{\circ}\right)$ to the left or right of the central array. The distance between the letters in the central array was $0.9^{\circ}$. The target was colored red and the other letters were white. In addition, the congruency of T2 was manipulated. When a letter which was assigned to the same response as the target letter was presented as a distractor, it was a congruent trial. However, when a letter which was assigned to a different response from the target was presented, it was an incongruent trial.

\section{Procedure}

There were six blocks of trials. The first and fourth blocks were practice blocks, composed of 36 trials each. The low set size display was presented in the second and third blocks of 160 trials and the high set size display in the fifth and sixth blocks of 160 trials, or vice versa. The total number of trials was 712. The order of display type was counter-balanced across participants.

Figure 2 depicts an example trial sequence. In each trial, the fixation display was presented for $500 \mathrm{~ms}$, followed by $100-\mathrm{ms}$ interval with a blank display. Participants were asked to stare at the fixation mark. A low or high tone was presented as S1. Participants were instructed to press the ' $z$ ' key of a standard computer keyboard to the low tone with their left middle finger and the ' $x$ ' key to the high tone with their left index finger. After $50 \mathrm{~ms}, 100 \mathrm{~ms}, 300 \mathrm{~ms}, 700 \mathrm{~ms}$, or $1100 \mathrm{~ms}$, the target display for T2 was presented. Participants were instructed to press the ' $n$ ' key with their right index finger when the target letter was

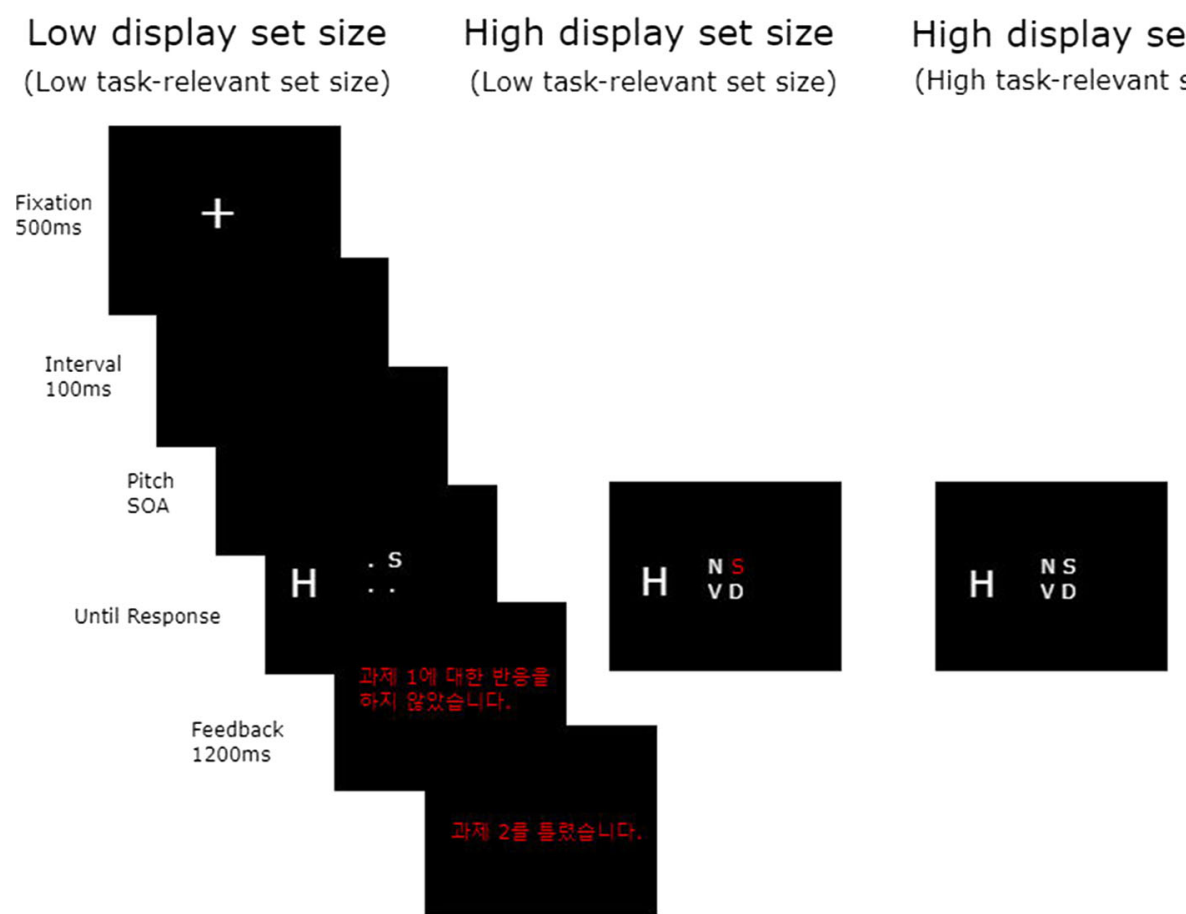

Fig. 2 An e xample of a trial sequence in Experiments 1 and 2. The two left displays were used in Experiment 1 and the two right displays in Experiment 2 
' $C$ ' or ' $S$ ' and the ' $\mathrm{m}$ ' key with their right middle finger when it was ' $H$ ' or ' $K$ ' while ignoring the peripheral distractor. Participants were instructed to respond to the target of T1 earlier than that of T2 and as fast and accurately as possible to both targets. In the case of a wrong response, a 50-ms auditory tone and a 1200-ms visual feedback display ("Incorrect" in Korean) was shown for the R1 and R2 (600 ms each).

\section{Results}

Trials were excluded if the RT1 was shorter than $125 \mathrm{~ms}$ or longer than $2000 \mathrm{~ms}$ ( $1 \%$ of all trials), or if the RT2 was shorter than $125 \mathrm{~ms}$ or longer than $2500 \mathrm{~ms}$ (1\% of all trials). Also, trials with incorrect responses on either task were excluded in RT analyses (3\% for PE1 and 5\% for PE2 of all trials). The mean RTs and proportion of errors (PEs) were calculated for each participant as a function of display set size (high and low), congruency (congruent and incongruent), and SOA (50 ms, $100 \mathrm{~ms}, 300 \mathrm{~ms}, 700 \mathrm{~ms}$, and $1100 \mathrm{~ms}$ ). Analyses of variance (ANOVAs) were conducted on the mean RTs and PEs data of T1 and T2, with these variables as withinsubject factors. RT and PE data for Task 1 and Task 2 are shown in Tables 1 and 2, respectively.

\section{RT and PE of Task 1}

The main effect of display set size was significant $F(1,39)=$ 5.03, $P=.0307, M S e=24,511, \eta_{p}^{2}=.1142$. Mean RT1 was shorter when display set size was high $(M=573 \mathrm{~ms})$ than when it was low $(M=598 \mathrm{~ms})$. The main effect of SOA was also significant, $F(4,156)=7.34, P=<.0001, M S e=5329, \eta_{p}^{2}$ $=.1583$. Mean RT1 was $608 \mathrm{~ms}, 595 \mathrm{~ms}, 573 \mathrm{~ms}, 574 \mathrm{~ms}$, and $576 \mathrm{~ms}$ for $50-\mathrm{ms}, 100-\mathrm{ms} 300-\mathrm{ms}, 700-\mathrm{ms}$, and $1100-\mathrm{ms}$ SOAs, respectively. No other effect was significant.

The PE1 analysis revealed no significant main effect or interaction.

\section{RT and PE of Task 2}

Even though the mean RT2 tended to be shorter when display set size was high $(M=697 \mathrm{~ms})$ than when it was low $(M=721$ $\mathrm{ms})$, the main effect of display set size was not significant, $F(1,39)=2.48, P=.1233, M S e=48,017$. The main effect of congruency was significant, $F(1,39)=13.04, P=.0009, \mathrm{MSe}$ $=2246, \eta_{p}^{2}=.2506$. The mean RT2 was shorter in congruent trials $(M=703 \mathrm{~ms})$ than incongruent trials $(M=715 \mathrm{~ms})$. The main effect of SOA was significant, $F(4,156)=297.38, P<$ $.0001, M S e=9080, \eta_{p}^{2}=.8841$, indicating a PRP effect. The mean RT decreased as SOA increased $(M \mathrm{~s}=876 \mathrm{~ms}, 811 \mathrm{~ms}$, $676 \mathrm{~ms}, 599 \mathrm{~ms}$, and $583 \mathrm{~ms}$ for SOAs of $50 \mathrm{~ms}, 100 \mathrm{~ms}, 300$ $\mathrm{ms}, 700 \mathrm{~ms}$, and $1100 \mathrm{~ms}$, respectively). The interaction between display set size and congruency was significant, $F(1$, 39) $=10.49, P=.0025, M S e=48,017, \eta_{p}^{2}=.2120$. As in Fig. 3 , a significant congruency effect was found when display set size was low $(20 \mathrm{~ms}), F(1,39)=22.88, P<.0001, M S e=$ $1744, \eta_{p}^{2}=.3697$, but not when it was high $(4 \mathrm{~ms}), F(1,39)=$ $1.06, P=.3095, M S e=1683$. Importantly, the interaction of SOA and display set size was not significant, $F(4,156)<1$. The mean RTs were $894 \mathrm{~ms}, 821 \mathrm{~ms}, 687 \mathrm{~ms}, 609 \mathrm{~ms}$, and $596 \mathrm{~ms}$ for SOA $50 \mathrm{~ms}, 100 \mathrm{~ms}, 300 \mathrm{~ms}, 700 \mathrm{~ms}$, and 1100 $\mathrm{ms}$, respectively, when display set size was low, and $858 \mathrm{~ms}$, $802 \mathrm{~ms}, 666 \mathrm{~ms}, 589 \mathrm{~ms}$, and $570 \mathrm{~ms}$, respectively, when it was high (see Fig. 4). Therefore, the display set size effect did not significantly change across SOAs $(35 \mathrm{~ms}, 20 \mathrm{~ms}, 21 \mathrm{~ms}$, $20 \mathrm{~ms}$, and $26 \mathrm{~ms}$ for SOAs of $50 \mathrm{~ms}, 100 \mathrm{~ms}, 300 \mathrm{~ms}, 700$ $\mathrm{ms}$, and $1100 \mathrm{~ms}$, respectively). When another ANOVA was conducted with display set size, congruency, and pooled SOA (the two shortest SOAs and the two longest SOAs) for more precise examination of this additivity, the interaction of pooled SOA and display set size was not significant, $F(1,39)<1$. The amount of the display set size effect was similar at the short SOAs (28 ms) and at the long SOAs (23 ms).

Also, the interaction of congruency and SOA was not significant, $F(4,156)=1.28, P=.2785, M S e=1816$. The magnitude of the congruency effect was $2 \mathrm{~ms}, 18 \mathrm{~ms}, 7 \mathrm{~ms}, 21 \mathrm{~ms}$,

Table 1 Mean response times (RT) (in miliseconds), percentages of errors (PE), and standard deviation (SD) (in parentheses) on T1 as a function of display set size, congruency, and stimulus onset asynchrony (SOA) in Experiment 1

\begin{tabular}{|c|c|c|c|c|c|c|c|c|c|c|}
\hline \multirow[t]{2}{*}{ SOA } & \multicolumn{2}{|l|}{50} & \multicolumn{2}{|l|}{100} & \multicolumn{2}{|l|}{300} & \multicolumn{2}{|l|}{700} & \multicolumn{2}{|l|}{1100} \\
\hline & M & $\mathrm{PE}$ & M & $\mathrm{PE}$ & M & $\mathrm{PE}$ & M & $\mathrm{PE}$ & M & $\mathrm{PE}$ \\
\hline \multicolumn{11}{|c|}{ Low display set size } \\
\hline Congruent & $630(148)$ & $2.92(4.19)$ & $604(130)$ & $2.30(3.56)$ & $586(145)$ & $2.79(4.86)$ & $582(139)$ & $2.90(3.88)$ & $594(149)$ & $2.36(3.40)$ \\
\hline Incongruent & $620(137)$ & $2.71(3.25)$ & $617(136)$ & $3.65(4.76)$ & $578(125)$ & $2.08(2.98)$ & $586(136)$ & $2.00(2.95)$ & $580(150)$ & $2.31(3.58)$ \\
\hline \multicolumn{11}{|c|}{ High display set size } \\
\hline Congruent & $592(127)$ & $2.72(4.07)$ & $580(118)$ & $2.48(4.51)$ & 567 (119) & $2.21(5.68)$ & $568(127)$ & $2.53(3.58)$ & $563(114)$ & $2.78(4.38)$ \\
\hline Incongruent & $591(123)$ & $3.61(4.98)$ & 578 (116) & $3.83(6.00)$ & $564(120)$ & $2.37(4.01)$ & $559(118)$ & $3.07(7.48)$ & $567(127)$ & $2.40(4.67)$ \\
\hline
\end{tabular}


Table 2 Mean RTs (in milliseconds), PE, and SD (in parentheses) on T2 as a function of display set size, congruency, and SOA in Experiment 1

\begin{tabular}{|c|c|c|c|c|c|c|c|c|c|c|}
\hline \multirow[t]{2}{*}{ SOA } & \multicolumn{2}{|l|}{50} & \multicolumn{2}{|l|}{100} & \multicolumn{2}{|l|}{300} & \multicolumn{2}{|l|}{700} & \multicolumn{2}{|l|}{1100} \\
\hline & M & $\mathrm{PE}$ & M & $\mathrm{PE}$ & M & PE & M & $\mathrm{PE}$ & M & $\mathrm{PE}$ \\
\hline \multicolumn{11}{|c|}{ Low display set size } \\
\hline Congruent & $893(180)$ & $6.23(6.07)$ & 807 (167) & $4.53(4.32)$ & $681(135)$ & $5.41(6.10)$ & $590(90)$ & $3.29(4.14)$ & $586(104)$ & $3.40(4.05)$ \\
\hline Incongruent & $895(181)$ & $5.52(5.33)$ & 835 (167) & $6.48(5.97)$ & $693(124)$ & $5.14(4.40)$ & $629(113)$ & $3.84(5.02)$ & $605(110)$ & $3.17(3.88)$ \\
\hline \multicolumn{11}{|c|}{ High display set size } \\
\hline Congruent & $857(171)$ & $5.51(4.65)$ & $798(158)$ & $3.48(3.94)$ & $665(143)$ & $4.19(4.49)$ & $629(113)$ & $3.71(4.02)$ & $567(91)$ & $3.88(4.20)$ \\
\hline Incongruent & $860(176)$ & $5.54(4.92)$ & 805 (165) & $4.63(4.15)$ & 667 (146) & $5.12(5.42)$ & $590(108)$ & $4.68(5.65)$ & $572(112)$ & $3.64(4.83)$ \\
\hline
\end{tabular}

and $12 \mathrm{~ms}$ for $50 \mathrm{~ms}, 100 \mathrm{~ms}, 300 \mathrm{~ms}, 700 \mathrm{~ms}$, and $1100 \mathrm{~ms}$ SOAs, respectively. The 3-way interaction of display set size, congruency, and SOA was not significant, either, $F(4,156)<$ 1. That is, the amount of the effect of display set size on the congruency effect was relatively constant across SOAs (-1 $\mathrm{ms}, 21 \mathrm{~ms}, 9 \mathrm{~ms}, 36 \mathrm{~ms}$, and $14 \mathrm{~ms}$ for $50 \mathrm{~ms}, 100 \mathrm{~ms}, 300$ $\mathrm{ms}, 700 \mathrm{~ms}$, and $1100 \mathrm{~ms}$ SOAs, respectively, see Fig. 5). When another ANOVA was conducted with pooled SOA to examine this additivity more precisely, the display set size effect on distractor interference did not significantly differ between the two shortest SOAs $(10 \mathrm{~ms})$ and the two longest SOAs $(25 \mathrm{~ms}), F(1,39)=1.12, P=.2959, M S e=1978$. There were no other significant main or interaction effects.

For PE2 data, the main effect of congruency was marginally significant, $F(1,39)=3.85, P=.0568, M S e=9, \eta_{p}^{2}=$ .0899 . PE2 was slightly higher in incongruent trials $(4.78 \%)$ than congruent trials $(4.36 \%)$. The main effect of SOA was significant, $F(4,156)=6.72, P=<.0001, M S e=18, \eta_{p}^{2}=$ .1470. PEs decreased as SOA increased $(5.7 \%, 4.78 \%$, $4.97 \%, 3.88 \%$, and $3.52 \%$ for SOA $50 \mathrm{~ms}, 100 \mathrm{~ms}, 300 \mathrm{~ms}$, $700 \mathrm{~ms}$, and $1100 \mathrm{~ms}$, respectively). The interaction of display set size and SOA was marginally significant, $F(4,156)=2.32$, $p=.0594, M S e=12, \eta_{p}^{2}=.0561$. The differences of PE2 between the two display set sizes were $0.35 \%, 1.45 \%$, $0.62 \%, 0.63 \%$, and $0.47 \%$ for $50 \mathrm{~ms}, 100 \mathrm{~ms}, 300 \mathrm{~ms}, 700$

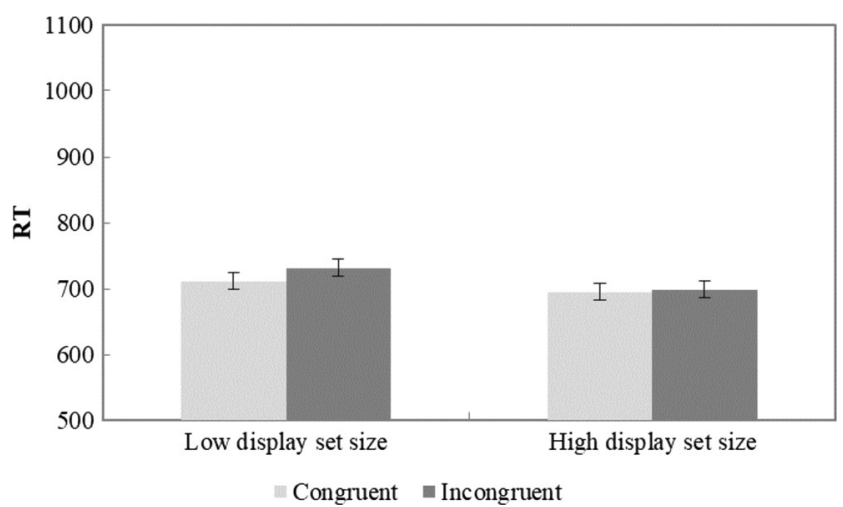

Fig. 3 Mean response time (RT) for Task 2 in Experiment 1 as a function of display set size and congruency $\mathrm{ms}$, and $1100 \mathrm{~ms}$ SOAs, respectively. No other effect was significant.

\section{Discussion}

As in previous PRP studies, a significant PRP effect was obtained in the present experiment, showing that RT2 decreased as SOA increased. Although participants were instructed to respond as fast as possible to $\mathrm{S} 1$, a display set size effect was obtained in RT1. These results indicate that participants might have used a strategy to respond to S1 after the response for T2 was selected. That is, they possibly selected R1 and hold it until R2 was ready to be executed (Pashler, 1984; Ulrich \& Miller, 2008). However, this was not the case in Experiment 1 because RT1 did not decrease linearly as the SOA increased and other S2 factors were not obtained in RT1.

As in Tsal and Benoni's (2010a) Experiment 1b, a significant display set size effect on distractor interference was obtained in the present experiment even though task-relevant set size was low in both displays. That is, the congruency effect was significantly smaller when display set size was high [4 $\mathrm{ms}, 95 \% \mathrm{CI}(-4.112 .5)]$ than when it was low [20 ms, 95\% CI $(11.5,28.4)]$. This result is inconsistent with the perceptual load theory, which assumes that the amount of interference is primarily determined by the number of task-relevant visual

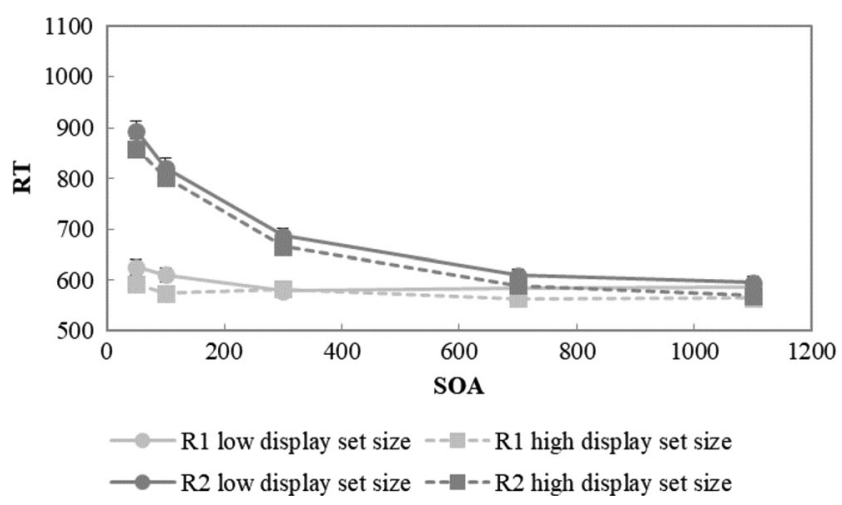

Fig. 4 Mean RT for Task 1 and Task 2 in Experiment 1 as a function of display set size and stimulus onset asynchrony (SOA: $50 \mathrm{~ms}, 100 \mathrm{~ms}, 300$ $\mathrm{ms}, 700 \mathrm{~ms}$, and $1100 \mathrm{~ms}$ ) 


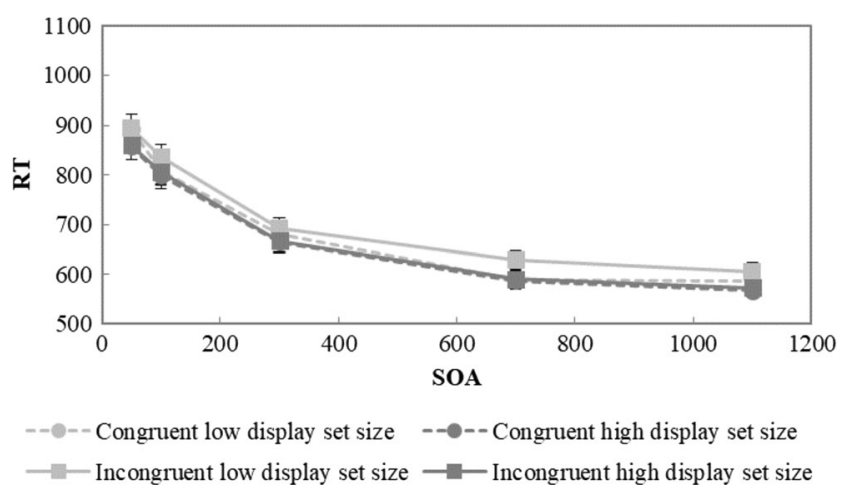

Fig. 5 Mean RT for Task 2 for congruent and incongruent trials in Experiment 1 as a function of display set size and SOA

items (Lavie \& Tsal, 1994). Regardless of their task relevance, the number of visual items in a display determined the degree to which the distractor was processed. More importantly, no interaction was found between display set size and SOA and the magnitude of the display set size effect on distractor interference was relatively constant across SOAs $(1 \mathrm{~ms}, 21 \mathrm{~ms}, 9$ $\mathrm{ms}, 36 \mathrm{~ms}$, and $14 \mathrm{~ms}$ for $50 \mathrm{~ms}, 100 \mathrm{~ms}, 300 \mathrm{~ms}, 700 \mathrm{~ms}$, and $1100 \mathrm{~ms}$ SOAs, respectively). These results indicate that display set size affected task performance at the focused attention stage so that the display set size effect on distractor interference occurred because of the limited capacity of attentional resources. If this effect was due to perceptual crosstalk at the preattentive stage, as Tsal and Benoni (2010a) suggested, the effects of display set size and the modulation of distractor interference by display set size should have increased with SOA because the perceptual processing of the distractor could continue during cognitive slack at short SOAs (Levy \& Pashler, 1995) even though the quality of the input to the letter recognition stage decreased with display set size. It has been suggested that perceptual processing for a stimulus is strengthened by recurrent processes until the offset of the stimulus (e.g., Francis, 1997). Thus, the results imply that the magnitude of distractor interference was modulated because of attentional competitions among visual items except the target in the search display at the focused attention stage, as Wilson et al. (2011) suggested.

\section{Experiment 2: the effect of task-relevant set size}

A larger congruency effect has been found when the task-relevant set size was high than when it was low (Tsal \& Benoni, 2010a), even though the original perceptual load theory suggest that the amount of distractor interference varies as an inverse function of taskrelevant set size (e.g., Lavie, 1995). According to Tsal and Benoni, the distractor was more likely processed when the task-relevant set size was high than when it was low because of a longer time window for target processing at the preattentive stage in the former than the latter, resulting in a higher probability of distractor intrusion. Wilson et al. (2011) also suggested that this reversed task-relevant set size effect on distractor interference was due to a higher decision noise when the task-relevant set size was high than when it was low. However, although many studies have obtained this reversed task-relevant set size effect on distractor interference (Tsal \& Benoni, 2010a; Wilson et al., 2011), it has not been reliably obtained in other studies (see Benoni \& Tsal, 2010).

In Experiment 2, the congruency effects were examined with a manipulation of task-relevant set size, as in the high load and dilution displays used in Tsal and Benoni's (2010a) Experiment 1b, in the dual-task context to see the nature of the task-relevant set size effect on distractor interference when the effect of display set size was controlled. As in Experiment 1, participants were asked to perform a tone discrimination task as $\mathrm{T} 1$ and a letter discrimination task as $\mathrm{T} 2$. When the relevant set size was high, a white target and three white neutral letters were presented at four central positions and a distractor at a peripheral position and, when it was low, the display was identical to the high display set size display used in Experiment 1.

If the amount of distractor interference is determined solely by perceptual load (Lavie, 1995; Lavie \& Tsal, 1994), a larger congruency effect would be obtained when the task-relevant set size was low than when it was high. However, if taskrelevant set size modulates the target selection efficiency, as Tsal and Benoni (2010a) and Wilson et al. (2011) suggested, task-relevant set size would have an underadditive effect with SOA. Moreover, if the probability of distractor intrusion is determined by the target search efficiency, the congruency effect would be larger when the task-relevant set size was high than when it was low. Also, this modulation would increase with SOA, because the target selection efficiency affects task performance at a processing stage before the target is processed at the focused attention stage. However, if the effects of task-relevant set size occur after the target letter is selected at the focused attention stage, they would have an additive effect with SOA.

\section{Method}

\section{Participants}

Forty new students from Korea University (19 females) with an age range between 19 and 35 years old participated and provided informed consent, as approved by the Institutional Review Board of Korea University. All had normal and corrected-to-normal visual acuity and color vision by self-report. None of the students had participated in Experiment 1. 
Apparatus, stimuli, design, and procedure

The apparatus, stimuli, design, and procedure of this experiment were almost identical to those used in Experiment 1, with the exception of T2's display type (Fig. 2). While high and low display set size displays were used for T2 in Experiment 1, high and low task-relevant set size displays, which were identical to the high load and dilution displays of Tsal and Benoni's (2010a) Experiment 1b, were used in Experiment 2. The low task-relevant set size display was identical to the high display set size display used in Experiment 1. On the high task-relevant set size display, a white-colored target was presented with three white neutral letters in the central square array and one distractor letter in the target display.

\section{Results}

With the same exclusion criteria as those in Experiment 1, 3\% of all trials were excluded based on the RT1 criteria and $2 \%$ based on the RT2 criteria were excluded in both PE and RT analyses. Incorrect trials were also excluded (3\% for PE1 and $4 \%$ for PE2) in RT analyses. The mean RTs and PEs were calculated for each participant as a function of task-relevant set size (high and low), congruency (congruent and incongruent), and SOA (50 ms, $100 \mathrm{~ms}, 300 \mathrm{~ms}, 700 \mathrm{~ms}$, and $1100 \mathrm{~ms}$ ). ANOVAs were conducted on the mean RTs and PEs data of T1 (see Table 3) and T2 (see Table 4), with these variables as within-subject factors.

\section{RT and PE of Task 1}

The main effect of SOA was not significant, $F(4,156)=1.35$, $P=.2539, M S e=23,836$. The interaction of SOA and taskrelevant set size was significant, $F(4,156)=7.09, P<.0001$, $M S e=3793, \eta_{p}^{2}=.1539$. The RT differences of the two taskrelevant set sizes were $18,23,-10,-37$, and $-22 \mathrm{~ms}$ for each SOA $50 \mathrm{~ms}, 100 \mathrm{~ms}, 300 \mathrm{~ms}, 700 \mathrm{~ms}$, and $1100 \mathrm{~ms}$, respectively.
For PE1 data, the main effect of SOA was significant, $F(4$, $156)=4.98, P=.0008, M S e=9, \eta_{p}^{2}=.1132$. The mean $\mathrm{PE}$ decreased as SOA increased $(3.12 \%, 2.49 \%, 2.2 \%, 2.23 \%$, and $1.71 \%$ for $50 \mathrm{~ms}, 100 \mathrm{~ms}, 300, \mathrm{~ms} 700 \mathrm{~ms}$, and $1100 \mathrm{~ms}$ SOAs). The interaction of congruency and SOA was significant, $F(4,156)=2.96, P=.0217, M S e=6, \eta_{p}^{2}=$ .0705 . However, the congruency effect did not linearly decrease as SOA increased $(-1.14 \%, 0.17 \%, 0.4 \%, 0.59 \%$, and $0.05 \%$ for $50 \mathrm{~ms}, 100 \mathrm{~ms}, 300 \mathrm{~ms}, 700 \mathrm{~ms}$, and $1100 \mathrm{~ms}$ SOAs). There was no significant main effect or interaction in the PE1 analysis.

\section{RT and PE of Task 2}

The main effect of task-relevant set size was significant, $F(1$, $39)=63.87, P<.0001, M S e=69,643, \eta_{p}^{2}=.6209$. The mean RT2 was greater when task-relevant set size was high $(M=$ $907 \mathrm{~ms})$ than when it was low $(M=758 \mathrm{~ms})$. The main effect of congruency was significant, $F(1,39)=26.92, P=<.0001$, $M S e=2506, \eta_{p}^{2}=.4084$. The mean RT2 was greater for incongruent trials $(M=842 \mathrm{~ms})$ than congruent trials $(M=823$ $\mathrm{ms})$. The main effect of SOA was significant, $F(4,156)=$ 230.87, $P<.0001, M S e=14,222, \eta_{p}^{2}=.8555$, reflecting a PRP effect. The mean RT2s of SOA, $50 \mathrm{~ms}, 100 \mathrm{~ms}, 300$ $\mathrm{ms}, 700 \mathrm{~ms}$, and $1100 \mathrm{~ms}$ were $995 \mathrm{~ms}, 960 \mathrm{~ms}, 821 \mathrm{~ms}$, $711 \mathrm{~ms}$, and $675 \mathrm{~ms}$, respectively. The interaction of taskrelevant set size and congruency was not significant, $F(1$, $39)=2.63, P=.1130, M S e=3227$, indicating no significant reversed task-relevant set size effect on distractor interference (see Fig. 6). A significant congruency effect was observed when task-relevant set size was high $(24 \mathrm{~ms}), F(1,39)=$ $22.55, P<.0001, M S e=2746, \eta_{p}^{2}=.3663$, and when it was low $(12 \mathrm{~ms}), F(1,39)=4.71, P=.0362, M S e=2988, \eta_{p}^{2}=$ 1077. The interaction of task-relevant set size and SOA was significant, $F(4,156)=2.66, p=.0349, M S e=4133, \eta_{p}^{2}=$ .0638. The difference of the mean RT2 between the high and low task-relevant set size displays tended to increase as SOA increased (127 ms, $144 \mathrm{~ms}, 144 \mathrm{~ms}, 161 \mathrm{~ms}$, and $169 \mathrm{~ms}$ for

Table 3 Mean RT (in milliseconds), PE, and SD (in parentheses) on T1 as a function of task-relevant set size, congruency, and SOA in Experiment 2

\begin{tabular}{|c|c|c|c|c|c|c|c|c|c|c|}
\hline \multirow[t]{2}{*}{ SOA } & \multicolumn{2}{|l|}{50} & \multicolumn{2}{|l|}{100} & \multicolumn{2}{|l|}{300} & \multicolumn{2}{|l|}{700} & \multicolumn{2}{|l|}{1100} \\
\hline & M & PE & M & PE & M & $\mathrm{PE}$ & M & PE & M & $\mathrm{PE}$ \\
\hline \multicolumn{11}{|c|}{ High task-relevant set size } \\
\hline Congruent & $682(186)$ & $3.42(3.47)$ & $679(190)$ & $2.45(2.68)$ & 659 (199) & $1.93(2.91)$ & $654(240)$ & $2.03(3.10)$ & $688(291)$ & $1.84(2.70)$ \\
\hline Incongruent & $687(187)$ & $2.18(3.83)$ & $678(183)$ & $2.75(3.45)$ & $648(197)$ & $2.69(3.24)$ & $651(239)$ & $2.87(3.91)$ & $682(296)$ & $2.00(2.78)$ \\
\hline \multicolumn{11}{|c|}{ Low task-relevant set size } \\
\hline Congruent & $661(187)$ & $3.97(5.49)$ & $643(176)$ & $2.36(3.84)$ & $659(187)$ & $2.07(3.02)$ & $694(224)$ & $1.83(2.89)$ & $713(280)$ & $1.53(2.89)$ \\
\hline Incongruent & $671(190)$ & $2.92(3.79)$ & 669 (179) & $2.41(3.26)$ & $668(206)$ & $2.11(2.94)$ & $686(233)$ & $2.17(3.76)$ & $703(275)$ & $1.47(2.67)$ \\
\hline
\end{tabular}


Table 4 Mean RTs (in milliseconds), PEs, and SD (in parentheses) on T2 as a function of task-relevant set size, congruency, and SOA in Experiment 2

\begin{tabular}{|c|c|c|c|c|c|c|c|c|c|c|}
\hline \multirow[t]{2}{*}{ SOA } & \multicolumn{2}{|l|}{50} & \multicolumn{2}{|l|}{100} & \multicolumn{2}{|l|}{300} & \multicolumn{2}{|l|}{700} & \multicolumn{2}{|l|}{1100} \\
\hline & M & $\mathrm{PE}$ & M & $\mathrm{PE}$ & M & $\mathrm{PE}$ & M & $\mathrm{PE}$ & M & $\mathrm{PE}$ \\
\hline \multicolumn{11}{|c|}{ High task-relevant set size } \\
\hline Congruent & 1047 (214) & $5.52(5.57)$ & $1015(224)$ & $4.16(4.05)$ & $885(220)$ & $3.64(4.09)$ & $780(163)$ & $2.64(3.75)$ & 747 (138) & $3.25(5.06)$ \\
\hline Incongruent & 1069 (212) & $5.35(5.42)$ & $1050(220)$ & $5.18(5.35)$ & $902(220)$ & $4.75(5.19)$ & $804(156)$ & $4.88(5.23)$ & $773(150)$ & $3.86(4.37)$ \\
\hline \multicolumn{11}{|c|}{ Low task-relevant set size } \\
\hline Congruent & $925(200)$ & $4.08(3.83)$ & 874 (199) & $3.51(4.49)$ & $736(180)$ & $3.53(3.61)$ & $630(119)$ & $4.00(3.82)$ & $596(93)$ & $3.66(4.72)$ \\
\hline Incongruent & 937 (196) & $4.84(3.91)$ & $903(200)$ & $3.59(3.58)$ & $763(210)$ & $4.29(4.41)$ & $632(127)$ & $4.11(4.36)$ & $585(96)$ & $4.33(4.30)$ \\
\hline
\end{tabular}

SOA $50 \mathrm{~ms}, 100 \mathrm{~ms}, 300 \mathrm{~ms}, 700 \mathrm{~ms}$, and $1100 \mathrm{~ms}$, respectively; see Fig. 7). However, the interaction of congruency and SOA was not significant, $F(4,156)=1.38, P=$ $.2424, \mathrm{MSe}=2487$. The magnitude of the congruency effect was $16 \mathrm{~ms}, 32 \mathrm{~ms}, 22 \mathrm{~ms}, 13 \mathrm{~ms}$, and $8 \mathrm{~ms}$ for $50 \mathrm{~ms}, 100 \mathrm{~ms}$, $300 \mathrm{~ms}, 700 \mathrm{~ms}$, and $1100 \mathrm{~ms}$ SOAs, respectively. The threeway interaction of task-relevant set size, congruency, and SOA was not significant, $F(4,156)<1$. Although the amount of the effect of task-relevant set size on distractor interference was $9 \mathrm{~ms}, 6 \mathrm{~ms},-10 \mathrm{~ms}, 22 \mathrm{~ms}$, and $37 \mathrm{~ms}$ for $50 \mathrm{~ms}, 100 \mathrm{~ms}$, $300 \mathrm{~ms}, 700 \mathrm{~ms}$, and $1100 \mathrm{~ms}$ SOAs, respectively (see Fig. 8), the effect of task-relevant set size on distractor interference was not significant even when the two shortest SOAs (8 ms) and the two longest SOAs $(30 \mathrm{~ms})$ were pooled, $F(1,39)=$ $1.68, P=.2026, \mathrm{MSe}=2867$.

For PE2 data, only the main effect of congruency was significant, $F(1,39)=13.2, P=.0008, M S e=10, \eta_{p}^{2}=.2529$. PE2 was lower in congruent trials $(3.7 \%)$ than incongruent trials $(4.52 \%)$. No other effect was significant.

\section{Discussion}

As in Experiment 1, a significant PRP effect was obtained in Experiment 2. The mean RT2 increased as SOA decreased. Although RT1 showed the interaction of SOA and taskrelevant set size, the main effect of SOA was not significant

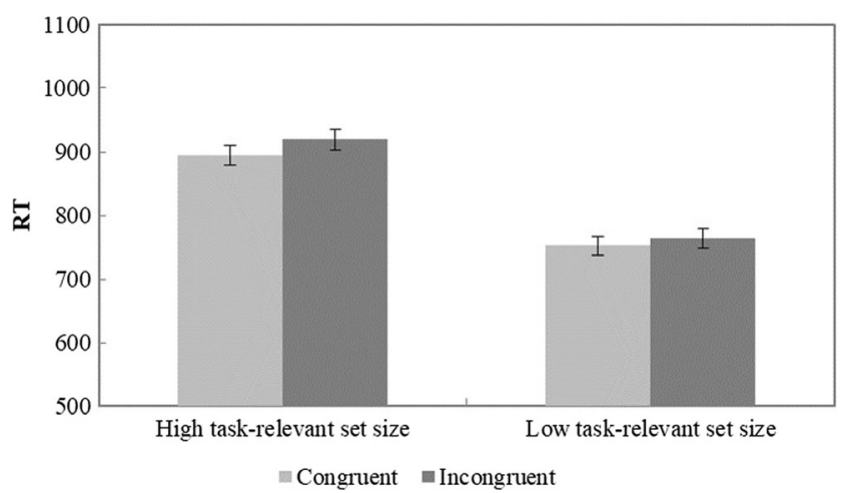

Fig. 6 Mean RT for Task 2 in Experiment 2 as a function of task-relevant set size and congruency and other S2 factors had no influence on RT1. Therefore, it is highly unlikely that this interaction might have been due to the result of capacity allocation as mentioned in the Discussion of Experiment 1.

To ascertain the effect of task-relevant set size without the influence of display set size, the congruency effects with the low and high task-relevant set sizes were compared in the dual-task context. The mean RT2 was greater when taskrelevant set size was high $(M=907 \mathrm{~ms})$ than when it was low $(M=758 \mathrm{~ms})$; it took longer to search for the target at the high task-relevant set size than the low task-relevant set size. In addition, importantly, task-relevant set size had an underadditive effect with SOA. That is, as shown in Fig. 7, the amount of the task-relevant set size effect on task performance increased with SOA (127 ms, $144 \mathrm{~ms}, 144 \mathrm{~ms}, 161 \mathrm{~ms}$, and $169 \mathrm{~ms}$ for $50 \mathrm{~ms}, 100 \mathrm{~ms}, 300 \mathrm{~ms}, 700 \mathrm{~ms}$, and $1100 \mathrm{~ms}$ SOAs, respectively). This result implies that, as Tsal and Benoni (2010a) suggested, the target selection efficiency at the preattentive stage was modulated by task-relevant set size. The target letter was efficient to find because it was easily distinguished from the other items by its unique color when task-relevant set size was low, while it took longer to find the target letter when it was high because the target letter did not pop out among non-target letters and the distractor when it was high. Therefore, distractor intrusion could have increased as a function of task-relevant set size at the preattentive stage.

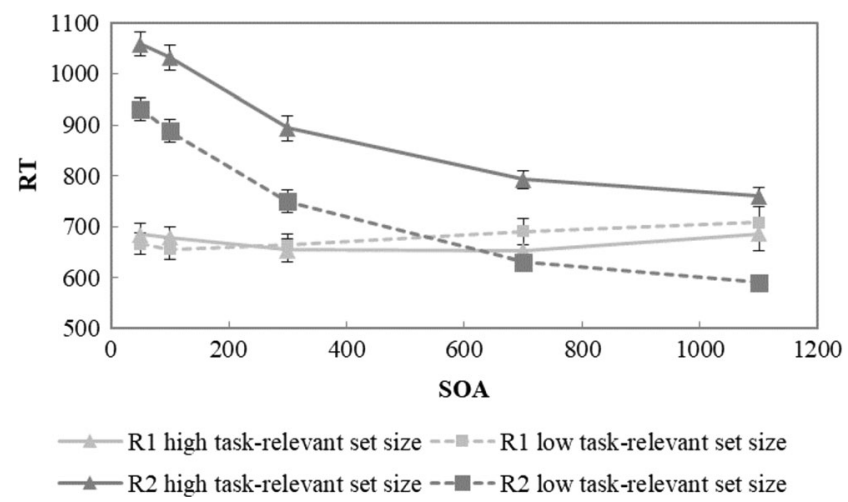

Fig. 7 Mean RT for Task 1 and Task 2 in Experiment 2 as a function of task-relevant set size and SOA 


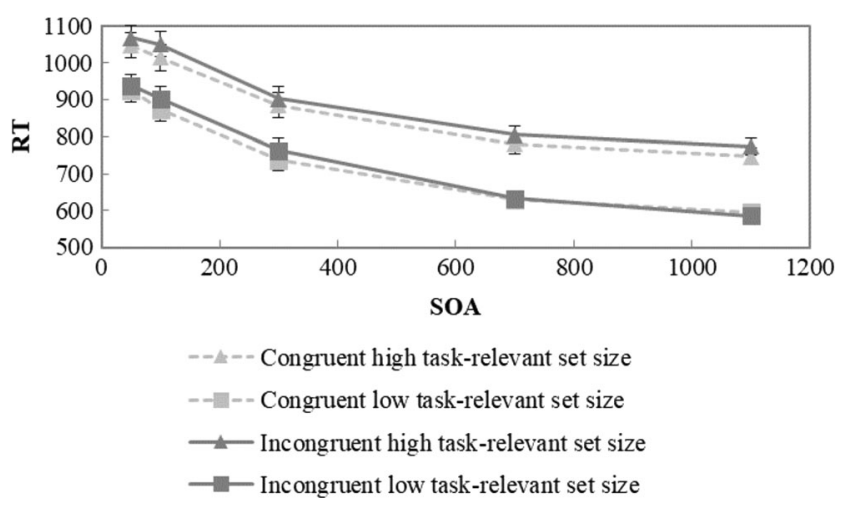

Fig. 8 Mean RT for Task 2 for congruent and incongruent trials in Experiment 2 as a function of task-relevant set size and SOA

Importantly, although the amount of distractor interference tended to be larger when task-relevant set size was high [24 $\mathrm{ms}, 95 \% \mathrm{CI}(14.3,35.5)]$ than when it was low [12 ms, 95\% CI $(0.8,22.9)]$, unlike the results of Tsal and Benoni's (2010a) Experiment $1 \mathrm{~b}$, this reversed task-relevant set size effect on distractor interference, which has not been reliably obtained in previous studies (e.g., Benoni \& Tsal, 2010), was not significant. This lack of the modulation of distractor interference by task-relevant set size was possibly due to infrequent misallocations of attention to the distractor regardless of task-relevant set size because of top-down attentional control sets or other bottom-up factors at the preattentive stage. It is important, however, to note that the lack of the interaction of taskrelevant set size, congruency, and SOA was possibly due to no task-relevant set size effect on distractor interference.

As in Experiment 1, the magnitude of the congruency effect was constant across SOAs. This result is consistent with the well accepted idea that the congruency effect is caused by a conflict between the responses activated by the target and the distractor stimulus features at the response selection processing stage, which is a limited capacity processing stage (Lien \& Proctor, 2002; McCann \& Johnston, 1992; Piai, Roelofs, \& Schriefers, 2014).

\section{General discussion}

To test whether display set size and task-relevant set size effects on distractor interference occur at a preattentive stage or at a focused attention stage, the present study examined distractor interferences of the second task in a dual-task context by manipulating display set size or task-relevant set size, as well as SOA. The basic rationale was that if an independent variable affected information processing at a stage for $\mathrm{T} 2$, which could occur in parallel with information processing at the focused attention stage for T1, the effect of the independent variable should increase with SOA. However, if this independent variable affected information processing, which cannot occur in parallel with the focused attention stage for $\mathrm{T} 1$ the variable should have an additive effect with SOA.

In Experiment 1, display set size was manipulated to examine the natures of the display set size effect on distractor interference while controlling task-relevant set size. As in Tsal and Benoni's (2010a) experiments, the amount of distractor interference was smaller when display set size was high than when it was low. However, importantly, this modulation of distractor interference by display set size, as well as display set size, had an additive effect with SOA. These results, which are inconsistent with Tsal and Benoni's idea that the display set size effect on distractor interference is due to perceptual crosstalk among visual items in a display at the preattentive stage, suggest that display set size affected information processing at the focused attention stage, as Wilson et al. (2011) claimed.

In Experiment 2, in which task-relevant set size was manipulated to examine the nature of the task-relevant set size effect on distractor interference while controlling display set size, the amount of distractor interference was not significantly modulated by task-relevant set size, indicating no reversed perceptual load effect. However, task-relevant set size itself had an underadditive effect with SOA, indicating that taskrelevant set size affected the efficiency of target selection at a processing stage before the target letter was processed at the focused attention stage, as Tsal and Benoni (2010a) and Wilson et al. (2011) suggested. That is, as task-relevant set size increases, the uncertainty regarding the target location increases and, consequently, the probability of distractor intrusion could increase. However, it is important to note that although the congruency effect was larger when task-relevant set size was high $(24 \mathrm{~ms})$ than when it was low $(12 \mathrm{~ms})$ and this effect tended to increase with SOA $(9 \mathrm{~ms}, 6 \mathrm{~ms},-10 \mathrm{~ms}$, $22 \mathrm{~ms}$, and $37 \mathrm{~ms}$ for $50 \mathrm{~ms}, 100 \mathrm{~ms}, 300 \mathrm{~ms}, 700 \mathrm{~ms}$, and $1100 \mathrm{~ms}$ SOAs, respectively) in Experiment 2, these effects were not statistically significant. The lack of the underadditivity between the modulation of distractor interference by task-relevant set size and SOA indicates that the misallocation of attention to the distractor before the target letter is processed at the focused attention stage is determined not only by task-relevant set size but also by other top-down and bottom-up factors, such as attentional control settings (e.g., Benoni et al., 2014), and perceptual similarity between the target and distractor (e.g., Yeh \& Lin, 2013). For example, distractor intrusion has been found to occur infrequently when the target and the distractor were perceptually distinguishable (Eltiti et al., 2005; Yeh \& Lin, 2013).

\section{Dilution in the focused attention stage}

To explain the effect of the display set size on distractor interference, Tsal and Benoni (2010a) proposed the dilution account, which is based on Brown et al.'s (Brown et al., 1995; 
Brown, Gore, \& Carr, 2002) early visual interference account. According to this account, all visual items in a display can be automatically recognized, so that responses are delayed when an incongruent distractor is presented. However, when multiple items are presented simultaneously in a display, feature representations of these visual items interfere with each other before lexical encoding, resulting in degraded inputs for word (or letter) recognition. Thus, the degree to which a distractor is processed varies as an inverse function of the number of visual items or the visual complexity in a display. However, the findings of the present study's Experiment 1 provide evidence counteracting the idea that dilution occurs because of this perceptual crosstalk at the preattentive stage. In fact, it has been reported that Stroop dilution is not modulated by perceptual factors, such as visual complexity (Mitterer, La Heij, \& Van der Heijden, 2003; Roberts \& Besner, 2005). For example, Roberts and Besner (2005) found no Stroop dilution when a string of complex symbols was presented as a color carrier. Moreover, Mitterer et al. (2003) showed that strings of perceptually complex symbol induced smaller Stroop dilution than strings of letters, pseudowords, and words when these were presented as a dilutor.

In contrast, Wilson et al.'s (2011) dilution account suggests that the focused attention stage is, in part, responsible for the display set size effect on distractor interference. In their experiments, distractor interference decreased as the number of items in a display increased regardless of their relevancy. According to the latter authors, after all items are processed in parallel during the preattentive stage, one item most likely to be the target is selected for processing at the focused attention stage. In this latter stage, only the selected item is relevant, and all the other items are responsible for dilution. As Wilson et al. (2011) noted, "crosstalk increases, which in turn degrades the distractor representation and reduces distractor interference" (p. 330) at the focused attention stage. The amount of dilution therefore increases with display set size.

It has been suggested that one critical reason for distractor intrusion at the focused attention stage is attentional competition between visual items in a display (Cho et al., 2006; Choi, Cho, \& Proctor, 2009; Gaspelin, Ruthruff, \& Jung, 2014; Kahneman \& Chajczyk, 1983; Mitterer et al., 2003). For example, Kahneman and Chajczyk (1983) suggested that dilution occurs because of attentional competition between the distractor and neutral stimuli. According to them, distractor interference is induced only when the distractor captures attention but not when the neutral stimulus does. In addition, Cho et al. (2006) claimed that the color carrier has attentional priority in the Stroop display in a top-down way because only the carrier has target-defining features specified in the attentional control settings and in a bottom-up way because only it has chromatic color. Once the color carrier has been processed, attentional competition is likely to occur among visual items other than the target in the display for some reasons (Kim, Cho, Yamaguchi, \& Proctor, 2008; Lachter, Forster, \& Ruthruff, 2004). Similarly, Gaspelin et al. (2014) argued that the distractor interference effect is caused by involuntary misallocations of attention to the distractor, which is called slippage. According to the latter authors, the probability of the misallocation of attention to the distractor decreases as display set size increases because non-target letters which have targetdefining features compete with the distractor for slippage of spatial attention. These slippage-based accounts are applicable to the results of the present study's Experiment 1. That is, the target was easy to select on the basis of its location when display set size was low and its color when display set size was high. Once the target had been selected to be processed at the focused attention stage, attentional competition among visual items other than the target occurred, resulting in a congruency effect varying as an inverse function of the number of the visual items, because the probability of the misallocation of attention to the distractor decreased with the number of the visual items. Specifically, the findings imply that the congruency effect can be modulated by the probability that the distractor captured attention after the target has been selected to process at the focused attention stage. In contrast, the response selection stage is most related to the central bottleneck stage because attentional resources are limited at the both stages.

\section{The task-relevant set size effect in the preattentive stage}

Since Lavie and Tsal (1994) proposed the perceptual load theory, this concept has played an important role as a "hybrid resolution of the early-late selection debate" (Benoni \& Tsal, 2013, p. 1). The original perceptual load theory assumes that perception has limited capacity but is not controlled voluntarily so that the perceptual load of the task-relevant items determines the locus of selection (Lavie, 1995; Lavie \& Cox, 1997; Lavie \& de Fockert, 2003; Lavie \& Fox, 2000; Lavie \& Tsal, 1994). In other words, the locus of selection is determined by "the perceptual load involved in relevant processing" (Lavie \& Cox, 1997, p. 395). Specifically, processing of the taskirrelevant distractor is weakened early because attention is highly selective when perceptual load is high, whereas attention resources spill over to the processing of the task-irrelevant distractor when perceptual load is low, resulting in distractor interference. However, it has been found that task-relevant set size increased the degree to which distractors were processed when display set size was controlled (Benoni \& Tsal, 2012; Benoni et al., 2014; Chen \& Cave, 2013; Tsal \& Benoni, 2010a; Wilson et al., 2011).

According to Tsal and Benoni (2010a), because of increased processing time when task-relevant set size is high the probability that distractor intrusion occurs increases. More specifically, Wilson et al. (2011) suggested that because 
the uncertainty regarding the target location increases at the preattentive stage as task-relevant set size increases, distractor intrusion is more likely to occur when task-relevant set size is high than when it is low. In other words, the degree to which the distractor is processed is not directly determined by the perceptual load of the target display, but by the efficiency in the target selection based on the outcomes of the information processing at the preattentive stage. Studies have consistently found that distractor interference increases as the target selection efficiency decreases, regardless of perceptual load (Chen, 2003; Cosman \& Vecera, 2012; Eltiti et al., 2005; Paquet \& Craig, 1997). The efficiency of the target selection is modulated by both bottom-up and top-down factors at the preattentive stage (e.g., Wolfe, 1994).

It is important to note that the task-relevant set size effect on distractor interference was modulated by top-down attentional set (Benoni et al., 2014; Theeuwes, Kramer, \& Belopolsky, 2004), but the display set size effect on distractor interference was not (Benoni et al., 2014). In Benoni et al.'s experiment, a marginally significant reversed task-relevant set size effect on distractor interference was found when the high and low set size displays were randomly presented, but no effect when the two types of display were presented in different experiment blocks. These results indicate that as the efficiency in selecting a target from a task-irrelevant distractor, which is determined by top-down attentional control settings, decreases in the preattentive stage, the processing of the distractor is more likely to occur before the target is selected to process. Thus, the reversed task-relevant set size effect on the congruency will be found only when the distractor is selected before the target in the high task-relevant set size condition because of a low selection efficiency. Specifically, as the uncertainty of the target location increases with taskrelevant set size, the probability that distractor intrusion occurs before the target is selected for processing at the focused attention stage can increase, resulting in the congruency effect varying as a function of task-relevant set size.

Yeh and Lin (2013) found that efficiency of target selection also undergoes bottom-up modulation from the perceptual similarity between the target and distractor. In their experiments, in which the target was determined by its location when display set size was high but task-relevant set size was low, a significant congruency effect was obtained only when the target and distractor were presented in the same color and other non-targets were in a different color, but not when the target and distractor were presented in different colors or all stimuli were the same color. Gaspelin et al. (2014) also found increased distractor interference when the target color cue was presented at the distractor location even with a high display set size and decreased interference when the target color cue was presented at the target location with a low display set size. These results indicate that the congruency effect can be modulated by top-down and bottom-up factors affecting the probability that the distractor captures attention (distractor intrusion) before the target is processed at the focused attention stage.

\section{Conclusion}

When a target and a distractor are simultaneously presented with other visual items, the processing of the distractor could occur before or after the target is selected to process. The present study demonstrates that two important factors modulating the degree to which the distractor is processed - display set size and task-relevant set size-influenced information processing at different stages. Display set size modulates the congruency effect after the target has started to be processed at the focused attention stage because of attentional competition among the visual items other than the target. However, taskrelevant set size seems to modulate the congruency effect before the target is selected for processing because of attentional competition between the target and other visual items, including the distractor. More generally, the size of the congruency effect is determined by the probability of the misallocation of attention to the distractor after the target is selected for processing, such as the number of visual items in a display and factors affecting the target selection efficiency, such as task-relevant set size and perceptual similarity, respectively. Even though the question of whether the congruency effect occurs only when it captures attention remains unanswered, converging evidence implies that the effect of the distractor is modulated by the misallocation of attention to the distractor.

Acknowledgment This research was supported by the Korean Research Foundation Grant funded by the Korean Government (NRF2016R1D1A1A09918865).

\section{References}

Beck, D. M., \& Lavie, N. (2005). Look here but ignore what you see: Effects of distractors at fixation. Journal of Experimental Psychology: Human Perception and Performance, 31(3), 592-607.

Benoni, H., \& Tsal, Y. (2010). Where have we gone wrong? Perceptual load does not affect selective attention. Vision Research, 50(13), $1292-1298$.

Benoni, H., \& Tsal, Y. (2012). Controlling for dilution while manipulating load: Perceptual and sensory limitations are just two aspects of task difficulty. Psychonomic Bulletin \& review, 19(4), 631-638.

Benoni, H., \& Tsal, Y. (2013). Conceptual and methodological concerns in the theory of perceptual load. Frontiers in Psychology, 4 522, 1-7.

Benoni, H., Zivony, A., \& Tsal, Y. (2014). Attentional sets influence perceptual load effects, but not dilution effects. The Quarterly Journal of Experimental Psychology, 67(4), 785-792.

Biggs, A. T., \& Gibson, B. S. (2014). Visual salience can co-exist with dilution during visual selection. Journal of Experimental Psychology: Human Perception and Performance, 40(1), 7-14.

Broadbent, D. E. (1958). The selective nature of learning. In Perception and communication (pp. 244-267). Elmsford, NY: Pergamon. 
Brown, T. L., Gore, C. L., \& Carr, T. H. (2002). Visual attention and word recognition in Stroop color naming: Is word recognition" automatic?". Journal of Experimental Psychology: General, 131(2), 220240.

Brown, T. L., Roos-Gilbert, L., \& Carr, T. H. (1995). Automaticity and word perception: Evidence from Stroop and Stroop dilution effects. Journal of Experimental Psychology: Learning, Memory, and Cognition, 21(6), 1395-1411.

Chen, Z. (2003). Attentional focus, processing load, and Stroop interference. Attention, Perception, \& Psychophysics, 65(6), 888-900.

Chen, Z., \& Cave, K. R. (2013). Perceptual load vs. dilution: The roles of attentional focus, stimulus category, and target predictability. Frontiers in Psychology, 4, 327, 1-14.

Cho, Y. S., Lien, M. C., \& Proctor, R. W. (2006). Stroop dilution depends on the nature of the color carrier but not on its location. Journal of Experimental Psychology: Human Perception and Performance, 32(4), 826-839.

Choi, J. M., Cho, Y. S., \& Proctor, R. W. (2009). Impaired color word processing at an unattended location: Evidence from a Stroop task combined with inhibition of return. Memory \& Cognition, 37(6), 935-944.

Cosman, J. D., \& Vecera, S. P. (2012). Object-based attention overrides perceptual load to modulate visual distraction. Journal of Experimental Psychology: Human Perception and Performance, 38(3), 576-579.

Davis, R. (1957). The human operator as a single channel information system. Quarterly Journal of Experimental Psychology, 9(3), 119129

Deutsch, J. A., \& Deutsch, D. (1963). Attention: Some theoretical considerations. Psychological Review, 70(1), 80-90.

Eltiti, S., Wallace, D., \& Fox, E. (2005). Selective target processing: Perceptual load or distractor salience? Perception \& Psychophysics, 67(5), 876-885.

Forster, S., \& Lavie, N. (2008a). Attentional capture by entirely irrelevant distractors. Visual Cognition, 16(2-3), 200-214.

Forster, S., \& Lavie, N. (2008b). Failures to ignore entirely irrelevant distractors: The role of load. Journal of Experimental Psychology: Applied, 14(1), 73-83.

Forster, S., \& Lavie, N. (2009). Harnessing the wandering mind: The role of perceptual load. Cognition, 111(3), 345-355.

Francis, G. (1997). Cortical dynamics of lateral inhibition: Metacontrast masking. Psychological Review, 104(3), 572-594.

Gaspelin, N., Ruthruff, E., \& Jung, K. (2014). Slippage theory and the flanker paradigm: An early-selection account of selective attention failures. Journal of Experimental Psychology: Human Perception and Performance, 40(3), 1257-1273.

Johnson, D. N., McGrath, A., \& McNeil, C. (2002). Cuing interacts with perceptual load in visual search. Psychological Science, 13(3), 284 287.

Kahneman, D., \& Chajczyk, D. (1983). Tests of the automaticity of reading: Dilution of Stroop effects by color-irrelevant stimuli. Journal of Experimental Psychology: Human Perception and Performance, 9(4), 497-509.

Kim, H., Cho, Y. S., Yamaguchi, M., \& Proctor, R. W. (2008). Influence of color word availability on the Stroop color-naming effect. Perception \& Psychophysics, 70(8), 1540-1551.

Lachter, J., Forster, K. I., \& Ruthruff, E. (2004) Forty-five years after Broadbent (1958): Still no identification without attention. Psychological Review, 111, 880-913.

Lavie, N. (1995). Perceptual load as a necessary condition for selective attention. Journal of Experimental Psychology: Human Perception and Performance, 21(3), 451-468.

Lavie, N., \& Cox, S. (1997). On the efficiency of visual selective attention: Efficient visual search leads to inefficient distractor rejection. Psychological Science, 8(5), 395-398.
Lavie, N., \& De Fockert, J. W. (2003). Contrasting effects of sensory limits and capacity limits in visual selective attention. Attention, Perception, \& Psychophysics, 65(2), 202-212.

Lavie, N., \& Fox, E. (2000). The role of perceptual load in negative priming. Journal of Experimental Psychology: Human Perception and Performance, 26(3), 1038-1052.

Lavie, N., \& Torralbo, A. (2010). Dilution: A theoretical burden or just load? A reply to Tsal and Benoni (2010). Journal of Experimental Psychology: Human Perception and Performance, 36(6), 16571664.

Lavie, N., \& Tsal, Y. (1994). Perceptual load as a major determinant of the locus of selection in visual attention. Perception \& Psychophysics, 56(2), 183-197.

Levy, J., \& Pashler, H. (1995). Does perceptual analysis continue during selection and production of a speeded response? Acta Psychologica, 90(1), 245-260.

Lien, M. C., \& Proctor, R. W. (2002). Stimulus-response compatibility and psychological refractory period effects: Implications for response selection. Psychonomic Bulletin \& Review, 9(2), 212-238.

Lien, M. C., Ruthruff, E., \& Johnston, J. C. (2006). Attentional limitations in doing two tasks at once: The search for exceptions. Current Directions in Psychological Science, 15(2), 8993.

McCann, R. S., \& Johnston, J. C. (1992). Locus of the single-channel bottleneck in dual-task interference. Journal of Experimental Psychology: Human Perception and Performance, 18(2), 471-484.

McCann, R. S., Remington, R. W., \& Van Selst, M. (2000). A dual-task investigation of automaticity in visual word processing. Journal of Experimental Psychology: Human Perception and Performance, 26(4), 1352-1370.

Mitterer, H., La Heij, W., \& Van der Heijden, A. (2003). Stroop dilution but not word-processing dilution: Evidence for attention capture. Psychological Research, 67(1), 30-42.

Murphy, G., Groeger, J. A., \& Greene, C. M. (2016). Twenty years of load theory-Where are we now, and where should we go next? Psychonomic Bulletin \& Review, 23(5), 1316-1340.

Norman, D. A. (1968). Toward a theory of memory and attention. Psychological Review, 75(6), 522-536.

Paquet, L., \& Craig, G. L. (1997). Evidence for selective target processing with a low perceptual load flankers task. Memory \& Cognition, 25(2), 182-189.

Pashler, H. (1984). Processing stages in overlapping tasks: Evidence for a central bottleneck. Journal of Experimental Psychology: Human Perception and Performance, 10(3), 358-377.

Pashler, H. (1994). Dual-task interference in simple tasks: Data and theory. Psychological Bulletin, 116(2), 220-244.

Piai, V., Roelofs, A., \& Schriefers, H. (2014). Locus of semantic interference in picture naming: Evidence from dual-task performance. Journal of Experimental Psychology: Learning, Memory, and Cognition, 40(1), 147-165.

Roberts, M. A., \& Besner, D. (2005). Stroop dilution revisited: Evidence for domain-specific, limited-capacity processing. Journal of Experimental Psychology: Human Perception and Performance, 3l(1), 3-13.

Schweickert, R. (1978). A critical path generalization of the additive factor method: Analysis of a Stroop task. Journal of Mathematical Psychology, 18(2), 105-139.

Schweickert, R. (1983). Latency network theory: Scheduling of processes in sentence verification and the Stroop effect. Journal of Experimental Psychology: Learning, Memory, and Cognition, 9(3), 353-383.

Theeuwes, J., Kramer, A. F., \& Belopolsky, A. V. (2004). Attentional set interacts with perceptual load in visual search. Psychonomic Bulletin \& Review, 11(4), 697-702.

Tsal, Y., \& Benoni, H. (2010a). Diluting the burden of load: Perceptual load effects are simply dilution effects. Journal of Experimental 
Psychology: Human Perception and Performance, 36(6), 16451656.

Tsal, Y., \& Benoni, H. (2010b). Much dilution little load in Lavie and Torralbo's (2010) response: A reply. Journal of Experimental Psychology: Human Perception and Performance, 36(6), 16651668.

Ulrich, R., \& Miller, J. (2008). Response grouping in the psychological refractory period (PRP) paradigm: Models and contamination effects. Cognitive Psychology, 57(2), 75-121.

Wei, P., Kang, G., \& Zhou, X. (2013). Attentional selection within and across hemispheres: Implications for the perceptual load theory. Experimental brain research, 225(1), 37-45.
Welford, A. T. (1952). The 'psychological refractory period' and the timing of high-speed performance - A review and a theory. British Journal of Psychology. General Section, 43(1), 2-19.

Wilson, D. E., Muroi, M., \& MacLeod, C. M. (2011). Dilution, not load, affects distractor processing. Journal of Experimental Psychology: Human Perception and Performance, 37(2), 319-335.

Wolfe, J. M. (1994). Guided search 2.0 a revised model of visual search. Psychonomic Bulletin \& Review, 1(2), 202-238.

Yeh, Y. Y., \& Lin, S. H. (2013). Two mechanisms of distractor dilution: Visual selection in a continuous flow. Journal of Experimental Psychology: Human Perception and Performance, 39(3), 872-892. 